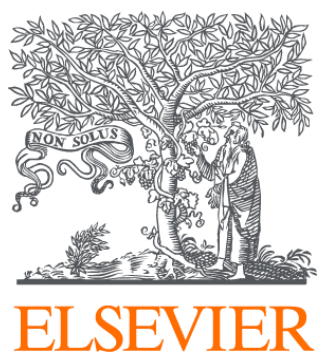

Since January 2020 Elsevier has created a COVID-19 resource centre with free information in English and Mandarin on the novel coronavirus COVID-

19. The COVID-19 resource centre is hosted on Elsevier Connect, the company's public news and information website.

Elsevier hereby grants permission to make all its COVID-19-related research that is available on the COVID-19 resource centre - including this research content - immediately available in PubMed Central and other publicly funded repositories, such as the WHO COVID database with rights for unrestricted research re-use and analyses in any form or by any means with acknowledgement of the original source. These permissions are granted for free by Elsevier for as long as the COVID-19 resource centre remains active. 


\title{
Factors Influencing In-hospital Mortality in Community-Acquired Pneumonia*
}

\author{
A Prospective Study of Patients Not Initially \\ Admitted to the ICU
}

Thomas J. Marrie, MD; and LieLing Wu, MSc

\begin{abstract}
Purpose: To determine the factors that predict in-hospital mortality among patients who require hospitalization for the treatment of community-acquired pneumonia (CAP).

Study design: Prospective observational study of all patients who were admitted to six hospitals in Edmonton, AL, Canada, with a diagnosis of CAP from November 15, 2000, to November 14, 2002. Pneumonia was defined as two or more respiratory symptoms and signs and an opacity on a chest radiograph as interpreted by the attending physician.

Results: A total of 3,043 patients were enrolled in the study, 246 of whom died $(8.1 \%)$. On multivariate analysis, increasing pneumonia severity score, increasing age, site of care, consultation with a respirologist or infectious diseases physician, and functional status at the time of admission were all independently predictive of mortality. Increasing pneumonia severity risk score, increasing age, site of hospitalization, functional status, and consultation with an infectious diseases physician or a respirologist were independently associated with both early $(<5$ days) and late ( $\geq 5$ days) mortality. In contrast, partial or complete use of the pneumonia pathway was associated with decreased early mortality, but had no effect on late mortality. A low lymphocyte count and a high serum potassium level were associated with early but not with late mortality. The type of antibiotic therapy had an effect on late but not on early mortality.

Conclusions: Functional status at the time of hospital admission is a powerful predictor of mortality and should be incorporated into any scores or models that are used to predict mortality. While there are some common predictors of early and late in-hospital mortality, early mortality is not affected by the timing or type of antibiotic therapy, whereas late mortality is influenced by the type of antibiotic therapy. Hyperkalemia and lymphopenia are associated with early mortality.

(CHEST 2005; 127:1260-1270)
\end{abstract}

Key words: functional status; mortality; pneumonia

Abbreviations: $\mathrm{CAP}=$ community-acquired pneumonia; $\mathrm{CI}=$ confidence interval; $\mathrm{FSA}=$ forward sortation area; HRCT $=$ high-resolution $\mathrm{CT} ; \mathrm{OR}=$ odds ratio

ommunity-acquired pneumonia $(\mathrm{CAP})$ is a com-
mon illness with an incidence rate of approxi-
mately $11.6 / 1,000$ adults per year, ${ }^{1}$ of which approx-

*From the Department of Medicine, University of Alberta, Edmonton, AL, Canada.

This study was funded by an independent research establishment grant from the Alberta Heritage Foundation for Medical Research, and by grants in aid from Capital Health, Abbott Canada, Pfizer Canada, and Jannsen-Ortho Canada.

Dr. Marrie, in addition to the above funding, has served on an advisory board for Abbot, Canada, and has grants for other studies from Bristol-Myers Squibb Co., and Bayer Inc.

Manuscript received February 4, 2004; revision accepted October 14, 2004.

Reproduction of this article is prohibited without written permission from the American College of Chest Physicians (e-mail: permissions@chestnet.org).

Correspondence to: Thomas J. Marrie, MD, 2 F1.30 Walter C. Mackenzie Health Sciences Center, 8840112 St, Edmonton, AL T6G 2B7, Canada; e-mail: tom.marrie@ualberta.ca imately $30 \%$ require admission to hospital. ${ }^{2}$ The mean age of 43,642 patients hospitalized for treatment of CAP over a 5 -year period in Alberta was $65.8 \pm 19.7$ years $( \pm \mathrm{SD})$, and the median age was 71 years. ${ }^{3}$ The in-hospital mortality rate for patients with CAP is considerable and varies with the population studied. However, in administrative database studies, where large populations are available, the mortality rate ranges from 9.7 to $11 \% .3,4$

In the past few years, attention has been paid to processes of care and the impact of these on the outcome of pneumonia. Critical pathways are disease-specific management strategies that define the essential steps of a complex care process. ${ }^{5}$ Such pathways were introduced to try to reduce variations in care. We introduced a pneumonia pathway at all six hospitals that provide care for adults in the 
greater Edmonton area. The objective of this study was to determine the factors that influence inhospital mortality for patients with CAP and whether adherence to the pathway had an effect on mortality.

\section{Materials AND Methods}

\section{Study Sites}

This study involved all six hospitals in the Edmonton area (adult population of 666,505$)^{6}$ : two tertiary care hospitals, two hospitals that provided secondary and some tertiary care, and two community hospitals. This study was approved by the Research Ethics Committee at the University of Alberta.

\section{Development of Pneumonia Pathway}

A multidisciplinary team developed a comprehensive pathway for the management of CAP. ${ }^{7}$ The pathway consisted of an admission guideline, ${ }^{8}$ preprinted orders covering routine aspects of care, an algorithm for administration and discontinuation of supplemental oxygen, and antimicrobial therapy (levofloxacin orally or cefuroxime plus azithromycin IV were the options provided), but other options were not prohibited. Reminders to medical staff regarding assessment of vaccination status for pneumococcal and influenza vaccines were provided, and a recommendation for administration of these vaccines, if indicated, was included in the order sheet. In addition, counseling and literature regarding cessation of smoking were made available to those who were tobacco smokers. A three-part discharge algorithm was part of the pathway. Once the patients had achieved physiologic stability, ${ }^{9}$ as defined by an oral temperature of $\leq 37.5 \mathrm{C}$ for $24 \mathrm{~h}$, a respiratory rate of $\leq 24$ breaths/min for $24 \mathrm{~h}$, an oxygen saturation of $\geq 90 \%$ while breathing room air or a return to baseline saturation levels, and ability to eat and drink enough to maintain hydration, functional (get-up-and-go test ${ }^{10}$ and an assessment of activities of daily living if the patient failed the get-up-and-go test) and mini-mental status assessments were carried out. ${ }^{710,11}$ In the get-up-and-go test, the patient is asked to arise from a sitting position and walk $3 \mathrm{~m}$. If this can be done in $\leq 20 \mathrm{~s}$, the patient has passed the test. A score $>25 / 30$ on the mini-mental status examination was considered a passing grade. If these test results were satisfactory and comorbid illnesses were stable, the patient was deemed ready for discharge. In general, functional status and mental status assessments were performed only on those patients who were $\geq 65$ years of age. Functional status premorbid admission was categorized as walking, walking with assistance, and walking with a prosthesis; wheel chair or bed-bound status was also recorded.

\section{Pneumonia Definition}

Two or more symptoms or signs of CAP (cough [productive or nonproductive], pleuritic chest pain, shortness of breath, temperature $>38^{\circ} \mathrm{C}$, and crackles, or bronchial breathing on auscultation) plus radiographic evidence of pneumonia as interpreted by the emergency department physician or internal medicine consultant. Patients were excluded from the pathway if they required admission to intensive care from the emergency department, were believed to have aspiration pneumonitis (defined as pulmonary opacities in the presence of recent loss of consciousness, vomiting or observation of respiratory distress within $30 \mathrm{~min}$ of feeding), tuberculosis, and cystic fibrosis. Pregnant and nursing mothers and immunosuppressed patients $(>10 \mathrm{mg} / \mathrm{d}$ prednisone for $>1$ month or other immunosuppressive drugs) were also excluded. Those with HIV infection were excluded if the $\mathrm{CD}_{4}$ count was $<250 / \mu \mathrm{L}$. During the second year of the study, patients with aspiration pneumonia were included.

\section{Data Collection and Definitions}

Adherence to the pathway was classified as complete or partial. If all elements of the pathway were followed, adherence was complete; adherence was incomplete if one or more elements were not followed. The 1996 Canadian census data were used to provide the median household income for each neighborhood area (forward sortation area [FSA]) corresponding to the first three digits of the postal code from the hospitalization records. ${ }^{12}$ Two hundred forty-eight unique FSAs were identified in our data, $96.9 \%$ of which were within the province of Alberta. The categories of median household income were used as a marker for the socioeconomic status (SES) of the patients. Since some patients had multiple hospitalizations, the analyses were limited to the first hospitalization within the 30-day period. Due to the small number of events, the patients with the prosthesis functional status $(\mathrm{n}=11)$ and no antibiotics administered $(\mathrm{n}=46)$ were also excluded from the analyses. The site identification of each hospital was masked (A-F) to protect the identities of the participating institutions.

\section{Statistical Analysis}

The analyses were performed on software (SAS version 8.2; SAS Institute; Cary, NC). Complete case analyses were used throughout. Independent variables with high percentages of missing values were not evaluated in the analysis. Descriptive statistics such as means and proportions were presented, and the differences were tested using F-test or $\chi^{2}$ test. Univariate analysis was used to exclude predictors that lacked marginal relationship with the all-cause mortality. The predictors with $\mathrm{p}$ values $<0.25$ in the univariate logistic regression analysis were retained in the multivariate logistic regression model. The risk of death was evaluated using multivariate logistic regression and all factors were evaluated simultaneously, while adjusting for other factors in the model. The predictors selected in the final model were based on both numerical and clinical significance. Odds ratios (ORs) and nominal 95\% confidence intervals (CIs) were presented. Both c-statistic and the Hosmer and Lemeshow lack of fit test were used to evaluate the adequacy of the logistic regression models. Hierarchical logistic regression models with predictors added one at a time were also examined to evaluate the possible collinearity among the predictors. No significant collinearity among the factors was observed. Since the comorbidity and medical history of the patients were accounted for during the calculation of the pneumonia severity index, no further adjustment was made. Cox proportional hazard models, which accounted for time from admission to mortality, were also developed. The results from the proportional hazard model were similar to the ones from the multivariate logistic regression model, so they are not presented. A two-sided $p$ value $<0.05$ was considered significant for all analyses.

Since adherence to the pneumonia pathway varied among the sites of care, which may have resulted in the imbalances between the covariates, we used the logistic regression model to estimate the propensity of CAP pathway use during hospitalization. The propensity score method ${ }^{13,14}$ was chosen because of the following: (1) the CAP pathway was not a randomized intervention, and (2) many factors, as well as their interactions, affected the use of the pathway. The factors selected for the calculation of the propensity score included site, age, nursing home residence, 
residence with home care, gender, substance abuse, study year, season at the time of presentation, and median household income. The above variables and their interactions (up to five ways) were evaluated for their associations with CAP pathway used. Site, residence with home care, and their interaction were selected to calculate the estimated propensity score for the pathway use. The estimated propensity score of the CAP pathway was incorporated into the analysis of mortality as a covariate in the model. In addition to the estimated propensity score for the use of CAP pathway, the interaction between site and CAP pathway was also evaluated in the multivariate logistic regression model of mortality. The results from the model with the estimated propensity score (not shown), the model with site by pathway interaction (not shown), and the model with main effects only were very similar; hence, we chose to present the results from main effects only.

\section{RESUlts}

During the 2 years of the study (November 15, 2000 , to November 14, 2002), there were 3,043 patients with pneumonia (who met criteria for the pathway) admitted to the six Edmonton hospitals (Table 1). In addition, the following patients with a diagnosis of pneumonia were excluded from the study: 704 patients who required admission to an ICU from the emergency department; 352 patients with aspiration pneumonia (first year of the study only-these patients were included in the second year once the pneumonia pathway team had decided on antibiotic therapy for this subset of patients); physician choice $(\mathrm{n}=136)$; palliative care $(\mathrm{n}=$ 113); pregnancy $(\mathrm{n}=36)$; immunosuppressed $(\mathrm{n}=88)$; cystic fibrosis $(\mathrm{n}=22)$; WBC count $<1,000(\mathrm{n}=19)$; tuberculosis $(\mathrm{n}=11)$; nosocomial pneumonia $(\mathrm{n}=59)$, bronchiectasis $(\mathrm{n}=58)$; pulmonary fibrosis $(\mathrm{n}=78)$; bronchiolitis obliterans with organizing pneumonia $(\mathrm{n}=9)$; talc lung $(n=2)$; collagen vascular disease $(n=3)$; sepsis with no pneumonia $(n=7)$; exacerbation of COPD $(\mathrm{n}=15)$; diagnosis changed from pneumonia to another diagnosis by attending physician with $48 \mathrm{~h}$ of admission $(\mathrm{n}=80)$; HIV infection with CD4 count $<250(\mathrm{n}=42)$; and unknown reasons $(\mathrm{n}=121)$.

The admission rate to ICU from the emergency department varied from 0 (this community hospital did not have an ICU, and patients requiring ICU were transferred to one of the other hospitals) to $16 \%$. The rates of admission at the tertiary care hospitals were $11.6 \%$ and $16.7 \%$, respectively, and for the secondary care hospitals were $7.8 \%$ and $10.2 \%$; for the two community hospitals, rates of admission were 0 and $5.2 \%$, respectively. Admission to an ICU from the ward was uncommon, occurring in only 10 patients, 4 of whom died.

The mean age of the included patients was $69.6 \pm 17.7$ years; $52.5 \%$ were male patients, $47.5 \%$ were female patients, and 246 patients (8.1\%) died.
The site-specific mortality rate ranged from 6 to $13.3 \%$. Table 1 also shows that there were site differences in the mean age, mean pneumonia severity of illness score, mean time from presentation until the first dose of antibiotic, mean length of stay, and median household income. Thirty-one percent were admitted from a nursing home or from a residence where they required some care. Only $60.2 \%$ were fully ambulatory; $7.2 \%$ required a wheelchair, and $3.4 \%$ were bed bound. Three hundred seventy-six patients (12\%) had a limitation of care order. One hundred sixty-six patients $(5.4 \%)$ were taken off the pathway because of increasing severity of the pneumonia; 113 of these were transferred to ICU. Since all of these patients were eligible for the study at the time of hospital admission, they are included in the analysis.

One thousand fifty-one patients had the get-upand-go test done, and 441 patients (41.9\%) failed. Six hundred seventy-six patients had the mini-mental status examination done, and 311 patients (46\%) failed.

Table 2 compares selected features of those who survived pneumonia vs those who died. There are a number of instructive observations. Not unexpectedly, there were major differences in mean age, mean pneumonia severity risk score, and mean length of stay between the two groups. Also, the effect of functional status at the time of admission on subsequent mortality was striking. Thus, $4.0 \%$, $11.6 \%, 20.1 \%$, and $25.2 \%$ of those who were walking, walking with assistance, wheelchair, and bedridden, respectively, died. The mean ages for patients in each of these groups were 63.8, 80.0, 73.3, and 74.4 years, respectively. The mean pneumonia severity risk scores for patients in the four functional status categories were $90.6,117.3,113.7$, and 117.6 , respectively. Ten of the 610 patients (1.6\%) who passed the get-up-and-go test died, compared with 62 of the 441 patients $(14.0 \%)$ who failed this test. The group that passed this test was younger (77.3 years vs 81.6 years), had a lower mean risk score (102.2 vs 121.8), and a lower percentage of patients in risk classes IV and V (73\% vs $86 \%)$. There were major differences in mortality according to the site of hospitalization, with mortality rates ranging from 5.9 to $13.3 \%$. As shown in the multivariate analysis, site of care remained a significant predictor for mortality after simultaneously adjusting for other factors.

The type of antibiotic therapy seemed to influence the mortality rate. The mortality rate for the 1,672 patients who were treated with levofloxacin only was $5.3 \%$, while $5.4 \%$ of the 166 patients treated with cefuroxime plus azithromycin died. The mortality rate among the 1,205 patients who received any other antibiotic or antibiotic combination was $12.2 \%$. 
Table 1-Characteristics of Study Population by Site of Care*

\begin{tabular}{|c|c|c|c|c|c|c|c|c|}
\hline \multirow[b]{2}{*}{ Characteristics } & \multicolumn{6}{|c|}{ Site } & \multirow{2}{*}{$\begin{array}{c}\text { Total } \\
(\mathrm{n}=3,043)\end{array}$} & \multirow[b]{2}{*}{$\mathrm{p}$ Value } \\
\hline & $\mathrm{A}(\mathrm{n}=426)$ & $\mathrm{B}(\mathrm{n}=173)$ & $\mathrm{C}(\mathrm{n}=457)$ & $\mathrm{D}(\mathrm{n}=1,023)$ & $\mathrm{E}(\mathrm{n}=337)$ & $\mathrm{F}(\mathrm{n}=627)$ & & \\
\hline Age, yr & $70.9 \pm 17.3$ & $71.1 \pm 19.3$ & $71.3 \pm 16.9$ & $67.8 \pm 17.9$ & $71.0 \pm 17.4$ & $69.1 \pm 17.7$ & $69.6 \pm 17.7$ & 0.0011 \\
\hline Risk score & $100.9 \pm 36.3$ & $93.5 \pm 32.9$ & $104.1 \pm 34.1$ & $99.1 \pm 36.4$ & $102.6 \pm 35.2$ & $104.3 \pm 32.7$ & $101.2 \pm 35.1$ & 0.0009 \\
\hline $\begin{array}{l}\text { Hours from presenting to } \\
\text { emergency department to } \\
\text { administration of the first } \\
\text { antibiotics (mean) }\end{array}$ & $9.4 \pm 14.8$ & $7.4 \pm 12.1$ & $7.2 \pm 13.1$ & $9.6 \pm 16.6$ & $6.1 \pm 7.1$ & $8.6 \pm 10.1$ & $8.5 \pm 13.6$ & 0.0002 \\
\hline Length of stay & $10.2 \pm 11.1$ & $10.3 \pm 16.4$ & $12.2 \pm 15.9$ & $12.3 \pm 14.6$ & $7.9 \pm 8.6$ & $10.6 \pm 13.0$ & $11.0 \pm 13.7$ & $<0.0001$ \\
\hline $\begin{array}{l}\text { Median household income, } \\
\text { thousand }\end{array}$ & $46.2 \pm 11.3$ & $46.0 \pm 6.0$ & $40.0 \pm 11.2$ & $33.1 \pm 10.2$ & $47.6 \pm 11.2$ & $38.6 \pm 12.4$ & $39.4 \pm 12.2$ & $<0.0001$ \\
\hline Mortality & $28(6.5)$ & $11(6.3)$ & $61(13.3)$ & $75(7.3)$ & $20(5.9)$ & $51(8.1)$ & $246(8)$ & 0.0005 \\
\hline Aboriginal origin & $8(1.8)$ & 0 & $19(4.2)$ & $53(5.2)$ & $8(2.4)$ & $25(3.9)$ & $113(3.7)$ & $<0.0001$ \\
\hline Nursing home residence & $59(13.8)$ & $17(9.8)$ & $54(11.8)$ & $83(8.1)$ & $36(10.6)$ & $42(6.7)$ & $291(9.6)$ & 0.0009 \\
\hline Residence with home care & $79(18.5)$ & $38(21.9)$ & $122(26.6)$ & $202(19.7)$ & $100(29.6)$ & $115(18.3)$ & $656(21.5)$ & $<0.0001$ \\
\hline Male gender & $198(46.5)$ & $81(46.8)$ & $234(51.2)$ & $560(54.7)$ & $181(53.7)$ & $344(54.8)$ & $1,598(52.5)$ & 0.1523 \\
\hline Ever substance abused & $14(3.3)$ & $4(0.9)$ & $32(7)$ & $171(16.7)$ & $10(2.9)$ & $60(9.5)$ & $291(9.5)$ & $<0.0001$ \\
\hline Passed get-up-and-go test, No. ${ }^{\dagger}$ & 76 & 56 & 101 & 151 & 45 & 181 & 610 & $<0.0001$ \\
\hline $\begin{array}{l}\text { Modified mini-mental score } \\
<25, \text { No. } \uparrow\end{array}$ & 37 & 23 & 43 & 121 & 39 & 48 & 311 & 0.0167 \\
\hline \multicolumn{9}{|l|}{ Risk class } \\
\hline 1 & $9(2.1)$ & $2(1.2)$ & $5(1.1)$ & $27(2.6)$ & $6(1.8)$ & $11(1.8)$ & $60(1.9)$ & 0.0048 \\
\hline 2 & $75(17.6)$ & $38(21.9)$ & $71(15.5)$ & $209(20.4)$ & $56(16.6)$ & $88(14)$ & $537(17.6)$ & \\
\hline 3 & $82(19.2)$ & $34(19.6)$ & $77(16.8)$ & $198(19.4)$ & $74(21.9)$ & $115(18.3)$ & $580(19.1)$ & \\
\hline 4 & $173(40.6)$ & $80(46.2)$ & $200(43.8)$ & $380(37.1)$ & $121(35.9)$ & $278(44.3)$ & $1,232(40.5)$ & \\
\hline 5 & $87(20.4)$ & $19(10.9)$ & $104(22.7)$ & $209(20.4)$ & $80(23.7)$ & $135(21.5)$ & $634(20.8)$ & \\
\hline \multicolumn{9}{|l|}{ Age group } \\
\hline$\leq 25$ & $7(1.6)$ & $5(2.8)$ & $6(1.3)$ & $15(1.5)$ & $9(2.6)$ & $8(1.3)$ & $50(1.6)$ & 0.0045 \\
\hline $25-65$ & $110(25.8)$ & $48(27.8)$ & $132(28.9)$ & $356(34.8)$ & $83(24.6)$ & $206(32.8)$ & $935(30.7)$ & \\
\hline$\geq 65$ & $309(72.5)$ & $120(69.4)$ & $319(69.8)$ & $652(63.7)$ & $245(72.7)$ & $413(65.8)$ & $2,058(67.6)$ & \\
\hline \multicolumn{9}{|l|}{ Study year } \\
\hline First year & $195(45.8)$ & $89(51.4)$ & $194(42.5)$ & $502(49.1)$ & $136(40.4)$ & $286(45.6)$ & $1,402(46.1)$ & 0.0271 \\
\hline Second year & $231(54.2)$ & $84(48.6)$ & $263(57.5)$ & $521(50.9)$ & $201(59.6)$ & $341(54.4)$ & $1641(53.9)$ & \\
\hline \multicolumn{9}{|l|}{ Smoking status } \\
\hline Unknown & $66(15.5)$ & $31(17.9)$ & $62(13.5)$ & $100(9.8)$ & $23(6.8)$ & $68(10.8)$ & $350(11.5)$ & $<0.0001$ \\
\hline Former smoker & $152(35.6)$ & $42(24.2)$ & $199(43.5)$ & $319(31.1)$ & $128(3.8)$ & $221(35.2)$ & $1,061(34.8)$ & \\
\hline Nonsmoker & $133(31.2)$ & $63(36.4)$ & $102(22.3)$ & $299(29.2)$ & $108(32)$ & $196(31.3)$ & $901(26.2)$ & \\
\hline Current smoker & $75(17.6)$ & $37(21.3)$ & $94(20.5)$ & $305(29.8)$ & $78(23.1)$ & $142(22.6)$ & $731(24)$ & \\
\hline \multicolumn{9}{|l|}{$\begin{array}{l}\text { Season visited emergency } \\
\text { department }\end{array}$} \\
\hline Spring & $126(29.5)$ & $58(33.5)$ & $145(31.7)$ & $298(29.1)$ & $105(31.1)$ & $189(30.1)$ & $921(30.2)$ & 0.8934 \\
\hline Summer & $80(18.7)$ & $32(18.5)$ & $104(22.7)$ & $219(21.4)$ & $66(19.5)$ & $121(19.2)$ & $622(20.3)$ & \\
\hline Fall & $92(21.5)$ & $33(19)$ & $87(19)$ & $223(21.7)$ & $64(18.9)$ & $130(20.7)$ & $629(20.6)$ & \\
\hline Winter & $128(30)$ & $50(28.9)$ & $121(26.5)$ & $283(27.6)$ & $102(30.2)$ & $187(29.8)$ & $871(28.6)$ & \\
\hline \multicolumn{9}{|l|}{$\begin{array}{l}1996 \text { FSA median household } \\
\text { income, thousand }\end{array}$} \\
\hline Unknown & $5(1.1)$ & $5(2.8)$ & $8(1.7)$ & $23(2.2)$ & $11(3.3)$ & $12(1.9)$ & $64(2.1)$ & $<0.0001$ \\
\hline$\leq 25$ & $8(1.8)$ & 0 & $16(3.5)$ & $261(25.5)$ & $11(3.3)$ & $49(7.8)$ & $345(11.3)$ & \\
\hline 25 to $\leq 35$ & $69(16.2)$ & $8(4.6)$ & $133(29.1)$ & $246(24)$ & $15(4.5)$ & $220(35)$ & $691(22.7)$ & \\
\hline 35 to $\leq 45$ & $97(22.7)$ & $42(24.2)$ & $166(36.3)$ & $377(36.8)$ & $106(31.4)$ & $190(30.3)$ & $978(32.1)$ & \\
\hline 45 to $\leq 55$ & $182(42.7)$ & $113(65.3)$ & $113(24.7)$ & $92(8.9)$ & $69(20.4)$ & $109(17.4)$ & $678(22.2)$ & \\
\hline$>55$ & $65(15.2)$ & $5(2.8)$ & $21(4.6)$ & $24(2.3)$ & $125(37)$ & $47(7.4)$ & $287(9.4)$ & \\
\hline \multicolumn{9}{|l|}{ Functional status } \\
\hline Walking without problem & $163(3.8)$ & $102(58.9)$ & $270(5.9)$ & $692(67.6)$ & $218(64.6)$ & $387(61.7)$ & $1,832(60.2)$ & $<0.0001$ \\
\hline Walking with assist & $184(43.1)$ & $52(11.3)$ & $160(35)$ & $216(21.1)$ & $100(29.6)$ & $177(28.2)$ & $889(29.2)$ & \\
\hline Wheelchair & $15(3.5)$ & $16(3.5)$ & $21(4.6)$ & $104(10.2)$ & $9(2.6)$ & $54(8.6)$ & $219(7.2)$ & \\
\hline Bedridden & $64(15)$ & $3(1.7)$ & $6(1.3)$ & $11(2.9)$ & $10(1.5)$ & $9(1.4)$ & $103(3.4)$ & \\
\hline \multicolumn{9}{|l|}{ Antibiotic therapy } \\
\hline Levofloxacin only & $299(70)$ & $87(50.3)$ & $269(58.8)$ & $524(51.2)$ & $155(45.9)$ & $338(53.9)$ & $1,672(54.9)$ & $<0.0001$ \\
\hline Cefuroxime plus azithromycin & $13(3)$ & $19(10.9)$ & $21(4.5)$ & $43(4.2)$ & $53(15.7)$ & $17(2.7)$ & $166(5.5)$ & \\
\hline Other antibiotics & $114(27)$ & $67(38.7)$ & $167(36.5)$ & $456(44.5)$ & $129(38.2)$ & $272(43.4)$ & 1,205 (39.6) & \\
\hline
\end{tabular}

*Data are presented as mean $\pm \mathrm{SD}$ or No. (\%) unless otherwise indicated.

†Percentage not calculated because of varying denominator. 
Table 2-Characteristics of Patients by Mortality Status*

\begin{tabular}{|c|c|c|c|c|}
\hline \multirow[b]{2}{*}{ Characteristics } & \multicolumn{2}{|c|}{ Mortality } & \multicolumn{2}{|c|}{ Total $(\mathrm{n}=3,043)$} \\
\hline & No $(\mathrm{n}=2,797)$ & Yes $(n=246)$ & & $\mathrm{p}$ Value \\
\hline Age, yr & $68.5 \pm 17.8$ & $81.2 \pm 10.9$ & $69.6 \pm 17.7$ & $<0.0001$ \\
\hline Risk score (pneumonia severity index) & $98.1 \pm 33.7$ & $136.4 \pm 30.7$ & $101.2 \pm 35.1$ & $<0.0001$ \\
\hline $\begin{array}{l}\text { Hours from present to emergency department } \\
\text { to administration of the first antibiotics }\end{array}$ & $8.4 \pm 13.3$ & $9.1 \pm 16.4$ & $8.5 \pm 13.6$ & 0.4807 \\
\hline Length of stay, d & $10.7 \pm 13.3$ & $14.6 \pm 16.8$ & $11.0 \pm 13.7$ & $<0.0001$ \\
\hline Median household income, thousands & $39.3 \pm 12.2$ & $40.5 \pm 12.4$ & $39.4 \pm 12.2$ & 0.1568 \\
\hline Aboriginal origin & 112 & $1(0.8)$ & 113 & 0.0167 \\
\hline Nursing home residence & 582 & $74(11.2)$ & 656 & 0.0007 \\
\hline Male & 1,464 & $134(8.3)$ & 1,598 & 0.7818 \\
\hline Passed get-up-and-go test & 600 & $10(1.6)$ & 610 & $<0.0001$ \\
\hline Modified mini-mental score $<25$ & 287 & $24(7.7)$ & 311 & 0.0026 \\
\hline Ever substance abused & 276 & $15(5.1)$ & 291 & 0.0539 \\
\hline \multicolumn{5}{|l|}{ Risk class } \\
\hline 1 & 60 & 0 & 60 & \multirow[t]{5}{*}{$<0.0001$} \\
\hline 2 & 532 & $5(0.9)$ & 537 & \\
\hline 3 & 568 & $12(2.1)$ & 580 & \\
\hline 4 & 1,152 & $80(13.8)$ & 1,232 & \\
\hline 5 & 485 & $149(23.5)$ & 634 & \\
\hline \multicolumn{5}{|l|}{ Age group, yr } \\
\hline$\leq 25$ & 50 & 0 & 50 & \multirow[t]{3}{*}{$<0.0001$} \\
\hline $25-65$ & 918 & $17(1.8)$ & 935 & \\
\hline$\geq 65$ & 1,829 & $229(11.1)$ & 2,058 & \\
\hline \multicolumn{5}{|l|}{ Site } \\
\hline A & 398 & $28(6.5)$ & 426 & \multirow[t]{6}{*}{0.0005} \\
\hline $\mathrm{B}$ & 162 & $11(6.3)$ & 173 & \\
\hline $\mathrm{C}$ & 396 & $61(13.3)$ & 457 & \\
\hline $\mathrm{D}$ & 948 & $75(7.3)$ & 1,023 & \\
\hline $\mathrm{E}$ & 317 & $20(5.9)$ & 337 & \\
\hline $\mathrm{F}$ & 576 & $51(8.1)$ & 627 & \\
\hline \multicolumn{5}{|l|}{ Study year } \\
\hline First year & 1,300 & $102(7.3)$ & 1,402 & \multirow[t]{2}{*}{0.1303} \\
\hline Second year & 1,497 & $144(8.7)$ & 1,641 & \\
\hline \multicolumn{5}{|l|}{ Smoking status } \\
\hline Unknown & 298 & $52(14.8)$ & 350 & \multirow[t]{4}{*}{$<0.0001$} \\
\hline Former smoker & 969 & $92(8.7)$ & 1061 & \\
\hline Nonsmoker & 830 & $71(7.8)$ & 901 & \\
\hline Current smoker & 700 & $31(4.2)$ & 731 & \\
\hline \multicolumn{5}{|l|}{ Season visited emergency department } \\
\hline Spring & 841 & $80(8.6)$ & 921 & \multirow[t]{4}{*}{0.5342} \\
\hline Summer & 572 & $50(8.0)$ & 622 & \\
\hline Fall & 574 & $55(8.8)$ & 629 & \\
\hline Winter & 810 & $61(7)$ & 871 & \\
\hline \multicolumn{5}{|l|}{1996 FSA median household income, thousand } \\
\hline Unknown & 60 & $4(6.2)$ & 64 & \multirow[t]{6}{*}{0.6232} \\
\hline$\leq 25$ & 324 & $21(6)$ & 345 & \\
\hline 25 to $\leq 35$ & 636 & $55(15.9)$ & 691 & \\
\hline 35 to $\leq 45$ & 898 & $80(8.1)$ & 978 & \\
\hline 45 to $\leq 55$ & 615 & $63(9.2)$ & 678 & \\
\hline$>55$ & 264 & $23(8)$ & 287 & \\
\hline Functional status & & & & \\
\hline Walking without problem & 1,759 & $73(3.9)$ & 1,832 & $<0.0001$ \\
\hline Walking with assist & 786 & $103(5.6)$ & 889 & \\
\hline Wheelchair & 175 & $44(20)$ & 219 & \\
\hline Bedridden & 77 & $26(25)$ & 103 & \\
\hline Antibiotic therapy & & & & \\
\hline Levofloxacin only & 1,583 & $89(5.3)$ & 1,672 & $<0.0001$ \\
\hline Cefuroxime plus azithromycin & 157 & $9(5.4)$ & 166 & \\
\hline Other antibiotics & 1,057 & $148(12.3)$ & 1,205 & \\
\hline
\end{tabular}

*Data are presented as mean $\pm \mathrm{SD}$, No., or No. (\%). 


\begin{tabular}{|c|c|c|c|}
\hline \multirow[b]{2}{*}{ Effect } & \multicolumn{3}{|c|}{ Logistic Regression of Mortality* } \\
\hline & p Value & OR & 95\% Wald Confidence Limits \\
\hline Risk score (per additional score) & $<0.001$ & 1.03 & $1.02-1.03$ \\
\hline Age (per additional year) & $<0.001$ & 1.03 & $1.01-1.04$ \\
\hline Functional status walking with assist vs walking without problem & 0.020 & 1.52 & $1.07-2.17$ \\
\hline Functional status wheelchair vs walking without problem & $<0.001$ & 2.92 & $1.84-4.63$ \\
\hline Functional status bedridden vs walking without problem & $<0.001$ & 5.36 & $2.79-10.26$ \\
\hline \multicolumn{4}{|l|}{ Site } \\
\hline A vs $\mathrm{E}$ & 0.758 & 0.90 & $0.45-1.79$ \\
\hline B vs E & 0.642 & 1.22 & $0.53-2.82$ \\
\hline C vs E & $<0.001$ & 3.08 & $1.70-5.56$ \\
\hline D vs E & 0.338 & 1.32 & $0.75-2.34$ \\
\hline F vs E & 0.118 & 1.61 & $0.89-2.92$ \\
\hline CAP pathway followed, partially used vs No & 0.094 & 0.70 & $0.46-1.06$ \\
\hline CAP pathway followed, yes vs no & 0.059 & 0.65 & $0.41-1.02$ \\
\hline Antibiotic therapy, levofloxacin only vs other antibiotics & $<0.001$ & 0.46 & $0.34-0.63$ \\
\hline Antibiotic therapy, cefuroxime plus azithromycin vs other antibiotics & 0.314 & 0.68 & $0.32-1.45$ \\
\hline Infectious/respiratory specialists consulted, yes vs no & $<0.001$ & 1.94 & $1.33-2.84$ \\
\hline
\end{tabular}

$*_{\mathrm{c}}$ statistic $=0.844, \mathrm{p}$ value for Hosmer and Lemeshow Lack of Fit Test $=0.7587$.

It is noteworthy that the time from presentation to the emergency department until the first dose of antibiotic did not influence mortality. In addition to the data provided in Table 1 , the mortality rates for the $1,235,1,078$, and 924 patients who received antibiotics within 0 to 4,4 to 8 , and $>8 \mathrm{~h}$ after presentation to the emergency department were $9.2 \%, 8.6 \%$, and $8.7 \%$, respectively. When we removed the patients who received antibiotics prior to presentation to the emergency department from the above data, the numbers of patients were $1,028,876$, and 712 , for 0 to $4 \mathrm{~h}, 4$ to $8 \mathrm{~h}$, and $>8 \mathrm{~h}$, respectively; and the corresponding mortality rates were $8.3 \%, 7.9 \%$, and $8.4 \%$.

One thousand nine hundred seventy-three patients $(64.8 \%)$ received a single antibiotic for the treatment of their pneumonia. Most of these, 1,838 patients $(93 \%)$ received levofloxacin only. One hundred eighty-eight patients $(6.2 \%)$ received cefuroxime and azithromycin only. An additional 628 patients received two antibiotics, 406 patients received three, 121 patients received four, and 77 patients received five or more antibiotics. In most instances, the multiple antibiotics represented sequential therapy.

Five factors were significantly associated with mortality in the multivariate analysis (Table 3): pneumonia severity of illness score, increasing age, site of care, consultation by a respirologist or an infectious diseases physician, and functional status at the time of admission (using a wheelchair or being bedridden at the time of hospital admission was associated with increased mortality). A fifth factor-treatment with levofloxacin only-was protective for mortality. In addition, compliance with the pathway was margin- ally associated with a reduction in mortality, although the significance was not as strong as the other factors identified above.

Table 4 compares those who died early, within 5 days of hospital admission, to those who died late, $\geq 5$ days after admission. Table 5 shows the factors that were associated with early and late mortality by multivariate analysis. Increasing pneumonia severity risk score, increasing age, site of hospitalization, functional status, and consultation with an infectious diseases physician or a respirologist were independently associated with both early and late mortality. In contrast, partial or complete use of the pneumonia pathway were marginally associated with decreased early mortality, but had no effect on late mortality. A low lymphocyte count and a high potassium level were associated with early, but not with late mortality. The type of antibiotic therapy had an effect on late but not on early mortality. Treatment with levofloxacin alone or with cefuroxime plus azithromycin was associated with decreased mortality compared with treatment with other antibiotics. Only one of the patients with a potassium level $>5$ $\mathrm{mmol} / \mathrm{L}$ had chronic renal failure and was receiving dialysis; however, 14 others had creatinine levels $>500 \mathrm{mmol} / \mathrm{L}$ indicating acute renal failure.

\section{Discussion}

It is evident that there are many factors that contribute to mortality among patients who require hospitalization for treatment of CAP. These can be grouped as patient factors, processes of care factors, physician factors, and other factors. Fine and co- 
Table 4-Comparison of Patients Who Died Within 5 Days of Hospital Admission (Early) vs Those Who Died $>5$ Days (Late) Following Admission*

\begin{tabular}{|c|c|c|c|c|c|}
\hline \multirow[b]{2}{*}{ Variables } & \multicolumn{3}{|c|}{ Time of Death } & \multirow[b]{2}{*}{ Total $(\mathrm{n}=3,043)$} & \multirow[b]{2}{*}{$\mathrm{p}$ Value } \\
\hline & Alive $(\mathrm{n}=2,797)$ & $\begin{array}{l}\text { Early Mortality }(\leq 5 \\
\text { Days) }(\mathrm{n}=100)\end{array}$ & $\begin{array}{c}\text { Late Mortality }(>5 \\
\text { Days) }(\mathrm{n}=146)\end{array}$ & & \\
\hline Age & $68.5 \pm 17.8$ & $81.9 \pm 9.5$ & $80.7 \pm 11.7$ & $69.6 \pm 17.7$ & $<0.0001$ \\
\hline Risk score & $98.1 \pm 33.7$ & $141.7 \pm 31.2$ & $132.8 \pm 30.0$ & $101.2 \pm 35.1$ & $<0.0001$ \\
\hline $\begin{array}{l}\text { Hours from time from presenting to } \\
\text { emergency department to administration } \\
\text { of the first antibiotics, } h\end{array}$ & $8.4 \pm 13.3$ & $8.3 \pm 13.2$ & $9.6 \pm 18.2$ & $8.5 \pm 13.6$ & 0.6183 \\
\hline Length of stay, d & $10.7 \pm 13.3$ & $3.4 \pm 1.8$ & $22.2 \pm 18.1$ & $11.0 \pm 13.7$ & $<0.0001$ \\
\hline Median household income, thousand & $39.3 \pm 12.2$ & $40.6 \pm 11.6$ & $40.4 \pm 13.0$ & $39.4 \pm 12.2$ & 0.3651 \\
\hline Male gender & 1,464 & 52 & 82 & 1,598 & 0.6647 \\
\hline \multicolumn{6}{|l|}{ Risk class } \\
\hline 1 & 60 & 0 & 0 & 60 & $<0.0001$ \\
\hline 2 & 532 & $2(0.3)$ & $3(0.5)$ & 537 & \\
\hline 3 & 568 & $1(0.2)$ & $11(1.8)$ & 580 & \\
\hline 4 & 1,152 & $34(2.7)$ & $46(3.7)$ & 1,232 & \\
\hline 5 & 485 & $63(9.9)$ & $86(13.5)$ & 634 & \\
\hline \multicolumn{6}{|l|}{ Site } \\
\hline A & 398 & $13(3)$ & $15(3.5)$ & 426 & 0.0035 \\
\hline $\mathrm{B}$ & 162 & $5(2.8)$ & $6(3.4)$ & 173 & \\
\hline $\mathrm{C}$ & 396 & $28(6.1)$ & $33(7.2)$ & 457 & \\
\hline $\mathrm{D}$ & 948 & $24(2.3)$ & $51(4.9)$ & 1,023 & \\
\hline $\mathrm{E}$ & 317 & $10(2.9)$ & $10(2.9)$ & 337 & \\
\hline $\mathrm{F}$ & 576 & $20(3.1)$ & $31(4.9)$ & 627 & \\
\hline \multicolumn{6}{|l|}{ Antibiotic therapy } \\
\hline Levofloxacin only & 1,583 & $38(2.3)$ & $51(3)$ & 1,672 & $<0.0001$ \\
\hline Cefuroxime plus azithromycin & 157 & $6(3.6)$ & $3(1.8)$ & 166 & \\
\hline Other & 1,057 & $56(4.6)$ & $92(7.6)$ & 1,205 & \\
\hline Lymphocytes $<1.0 \times 10^{9} / \mathrm{L}$ & 1,327 & $67(4.5)$ & $78(5.2)$ & 1,472 & 0.0003 \\
\hline Creatinine $>125 \mathrm{mmol} / \mathrm{L}$ & 563 & $49(7.5)$ & $39(5.9)$ & 651 & $<0.0001$ \\
\hline \multicolumn{6}{|l|}{ Potassium, mmol/L } \\
\hline Unknown & 126 & $3(2.3)$ & $1(0.7)$ & 130 & $<0.0001$ \\
\hline Normal & 2,142 & $65(2.8)$ & $113(4.8)$ & 2,320 & \\
\hline$<3.5$ & 368 & $10(2.5)$ & $16(4)$ & 394 & \\
\hline$>5.0$ & 161 & $22(11)$ & $16(8)$ & 199 & \\
\hline
\end{tabular}

*Data are presented as mean \pm SD, No., or No. (\%).

workers $^{8}$ derived a pneumonia severity of illness score based on 20 items that included demographic factors, comorbidity, physical examination findings, and laboratory and radiographic data. Scores ranged from 0 (no points are given for patients $\leq 50$ years of age without comorbidity and no physiologic abnormalities) to 250 , with higher scores indicating more severe pneumonia. In the original study, patients were grouped into five risk classes for mortality; classes I to III ( $\leq 90$ points) are at low risk for death, while the mortality rate in class IV was $9 \%$, and $27 \%$ in class $\mathrm{V}$. Since the mortality for patients in the risk classes I and II in our study was very low and insufficient for estimation, the pneumonia severity was analyzed as a continuous score. Even though age is the major driver in the Fine risk score (one point is given for each year of age for male subjects and 10 points are subtracted from the total age points for female subjects), we found that increasing age still contributed to the risk of mortality over and above that which was accounted for in the severity score. Thus, we carried out additional adjustment for age in the final logistic regression model due to the residual confounding. An additional independent association between age and mortality was observed in both multivariate logistic regression and Cox proportional hazard models.

The pneumonia severity score does not consider other factors that might be important in mortality, namely functional status, site of care, and processes of care. Ethnicity is also an important factor influencing mortality due to pneumonia. Haas et $\mathrm{al}^{15}$ found that Hispanics and Asian Americans had a lower risk of death from CAP than whites in California. In one study, African-American men admitted to Veterans Affairs hospitals in the United States had lower risk-adjusted mortality for a variety of conditions, including pneumonia. ${ }^{16}$ Most of the population of Alberta is white. One hundred thirteen of our patients $(3.7 \%)$ were Aboriginal Canadians. In an 
Table 5-Multivariate Logistic Regression Analysis of Factors Important in Early (Within 5 Days) and Late (> 5 Days) Mortality

\begin{tabular}{|c|c|c|c|c|}
\hline \multirow[b]{2}{*}{ Effect } & \multicolumn{2}{|c|}{ Early Mortality } & \multicolumn{2}{|c|}{ Late Mortality } \\
\hline & OR & $95 \% \mathrm{CI}$ & OR & $95 \% \mathrm{CI}$ \\
\hline Risk score (per additional score) & $1.024 *$ & $1.014-1.033$ & $1.025^{*}$ & $1.018-1.033$ \\
\hline Age (per additional year) & $1.044^{*}$ & $1.016-1.074$ & $1.028^{*}$ & $1.009-1.047$ \\
\hline \multicolumn{5}{|l|}{ Site } \\
\hline A vs $\mathrm{E}$ & 0.581 & $0.185-1.817$ & 0.863 & $0.315-2.361$ \\
\hline B vs $\mathrm{E}$ & 1.594 & $0.443-5.735$ & 1.089 & $0.295-9.014$ \\
\hline C vs E & $3.157^{*}$ & $1.241-8.032$ & $2.924^{*}$ & $1.265-6.758$ \\
\hline D vs $\mathrm{E}$ & 0.672 & $0.254-1.755$ & 1.533 & $0.690-3.494$ \\
\hline $\mathrm{F}$ vs $\mathrm{E}$ & 1.370 & $0.523-3.586$ & 1.597 & $0.689-3.703$ \\
\hline \multicolumn{5}{|l|}{ Functional status } \\
\hline Walking with assistance vs walking unassisted & 1.810 & $0.967-3.388$ & 1.229 & $0.771-1.959$ \\
\hline Wheelchair vs walking unassisted & $3.313^{*}$ & $1.457-7.533$ & $1.921^{*}$ & $1.037-3.558$ \\
\hline Bedridden vs walking unassisted & $8.287^{*}$ & $2.877-23.866$ & $3.657 *$ & $1.456-9.146$ \\
\hline Consult—infectious diseases/respirology & 1.965 & $0.984-3.923$ & $2.468^{*}$ & $1.559-3.905$ \\
\hline Pathway partial vs no use & $0.453^{*}$ & $0.233-0.882$ & 1.459 & $0.760-2.873$ \\
\hline Pathway completely used & $0.443^{*}$ & $0.216-0.909$ & 1.184 & $0.596-2.354$ \\
\hline Levofloxacin vs other & 0.643 & $0.380-1.090$ & $0.433^{*}$ & $0.289-0.647$ \\
\hline Cefuroxime/azithromycin vs other & 0.976 & $0.301-3.160$ & $0.223^{*}$ & $0.051-0.975$ \\
\hline Lymphocytes $<1$ yes vs no & $2.047^{*}$ & $1.206-3.477$ & 1.051 & $0.716-0.975$ \\
\hline Potassium $>5.0$ vs normal & $2.759 *$ & $1.411-5.397$ & 0.888 & $0.950-1.929$ \\
\hline Substance abuse yes vs no & $2.795^{*}$ & $1.091-7.161$ & & \\
\hline
\end{tabular}

*Statistically significant.

administrative database study of all persons admitted to hospital with pneumonia in Alberta over a 5-year period, patients of Aboriginal treaty status constituted $7 \%$ of the 43,642 comprising the study population. ${ }^{17}$ In that study, Aboriginal status was not associated with increased mortality. In the current study, the mortality rate among those of Aboriginal descent was very low at $0.8 \%$. However, these patients were considerably younger than the remainder of the pneumonia population and were more likely to be in risk classes I to III.

A major finding in this study was the contribution of functional status at the time of hospital admission as an independent predictor of mortality. Thus, patients who were in wheelchair or bedridden were 1.4 times and 4 times, respectively, more likely to die compared to patients who walked without problems. Two hundred nineteen persons $(7.1 \%)$ were using wheelchairs, and 103 persons (3.3\%) were bedridden. In a case-control study of 101 patients $\geq 65$ years of age with pneumonia, Riquelme et al ${ }^{18}$ reported a crude mortality rate of $26 \%$. Bedridden state had a relative risk of 10.75 for mortality. ${ }^{19}$ In a study of patients with COPD, Oga et al ${ }^{20}$ noted that exercise capacity and health status were significantly predictive of mortality independent of age or airflow limitation. Davis and co-workers ${ }^{21}$ studied persons admitted to a tertiary teaching hospital between 1987 and 1992 for cerebrovascular disease or pneumonia. They found that functional status had as much predictive value for in-hospital mortality as laboratory data. Indeed, the requirement for total assistance with bathing was the best single predictor of in-hospital mortality.

In a unique study, Salive et al ${ }^{19}$ followed up 6,234 men and 3,035 women $\geq 65$ years of age for up to 6 years. Two hundred forty-three men and 160 women died from pneumonia. Limitations in activities of daily living and cognitive impairment were independently associated with a significantly increased risk of pneumonia mortality.

Treatment with levofloxacin only was associated with a major reduction in mortality. Since this was not a randomized clinical trial, it is difficult to conclude that this effect was solely due to the antibiotic. The pathway encouraged levofloxacin use, and the fact that patients treated with levofloxacin only had low mortality could also indicate that physicians seldom change therapy in patients who are responding to treatment; indeed, this is confounding by indication. It also indicates that protocolized care with antibiotics consistent with guidelines $^{7}$ leads to lower mortality. Furthermore this observation does not demonstrate the superiority of a quinolone over a cephalosporin/macrolide combination. It is noteworthy, however, that we did not find that administration of antibiotic therapy $>8 \mathrm{~h}$ after presentation to the emergency department was associated with increased mortality, as has been described by others. ${ }^{22,23}$ Recently, Silber et al ${ }^{24}$ were 
also unable to show an association between time from arrival at the emergency department to antibiotic therapy, and time to achievement of stability or mortality in patients with CAP. In an illness that typically begins days before the patient presents to the hospital, it seems unusual that a delay of administration of antibiotic therapy of a few hours would be associated with an increased mortality rate. In the absence of data from randomized controlled trials, it is difficult to be sure that this is a real finding, even though as a standard of care timely administration of antibiotic therapy is appropriate. It is important to note that our study and that of Silber et $\mathrm{al}^{24}$ differed from the two studies ${ }^{22,23}$ that found an increased mortality rate if time from arrival to the emergency department to the first dose of antibiotics was prolonged, in that both of these studies dealt with Medicare patients who by definition were all $>65$ years of age. It is also noteworthy that Houck et al ${ }^{23}$ could not demonstrate such an effect for those who had received antibiotic therapy prior to presentation.

Treatment at hospital $\mathrm{C}$ was an independent risk factor for increased mortality in the overall, early, and late mortality models after the adjustment of other factors. Hospital factors such as teaching status, type of ownership, and location have been associated with differences in mortality for a variety of conditions. ${ }^{25,26}$ Understaffing of hospitals with nurses has also been associated with increased mortality. ${ }^{27}$ In our study, the hospital with a higher mortality rate is one of the three hospitals in Edmonton that does not have medicine house staff. In conjunction with the other hospitals, it is part of a regional health authority under one administration. We did not monitor nurse-staffing patterns as part of our study. Greater physician experience with pneumonia, as indicated by the number of patients treated in hospital with this illness per year, is reflected in a lower mortality rate. ${ }^{17}$ Thus, there are at least two factors that may have been different at the hospital with the higher mortality. At the end of the first year of the study, when we noted the higher mortality rate at hospital $\mathrm{C}$, we reviewed all the deaths from pneumonia and noted only one preventable death.

Requirement for consultation by an infectious diseases physician or a respirologist was associated with an increased mortality rate. Consultation was likely because of deterioration or a specific complication, thus indicating a complicated hospital course, $i e$, confounding by indication. The pneumonia severity score only measures severity at the time of hospital admission. An illness is dynamic, and serial measurements of severity of illness are necessary to understand the subsequent course of illness.

One of the most interesting findings in our study is that the risk factors for early and late mortality differed substantially. The type of antibiotic therapy affected only late mortality. Austrian and Gold, ${ }^{28}$ in a large study of bacteremic pneumococcal pneumonia in the early 1960s, noted that treatment with penicillin had no effect on mortality for the first 4 days of the illness. Mortensen et $\mathrm{al}^{29}$ carefully determined the causes of death of the 208 patients (9\%) who died within 90 days of enrollment in their study of CAP. Fifty-three percent of the deaths were pneumonia related. Factors predictive of pneumoniarelated mortality included hypothermia, altered mental state, increased serum urea nitrogen levels, chronic liver disease, leukopenia, and hypoxemia. Factors predictive of pneumonia-unrelated mortality included dementia, immunosuppressive conditions, active cancer, systolic hypotension, male gender, and multilobar pulmonary infiltrates. Increased age and evidence of aspiration were predictive of both pneumonia-related and -unrelated mortality.

In a study of 157 patients with severe ARDS (severe acute respiratory syndrome), 98\% had lymphopenia $\left(<1 \times 10^{9} / \mathrm{L}\right) .{ }^{28}$ Lymphopenia in severe acute respiratory syndrome patients peaked during week 2 . We recorded only the lymphocyte count at the time of hospital admission. In our study, $67 \%$ of those who died within 5 days of hospital admission were lymphopenic at hospital admission vs $29 \%$ of the survivors. For those who died $>5$ days after hospital admission, $53.4 \%$ were lymphopenic vs $43.8 \%$ for the survivors. Clearly, the role of the lymphocyte in pneumonia-related mortality requires further investigation. It should be noted that HIV status did not play a role in lymphopenia predicting mortality. Only $25 \mathrm{HIV}$-positive patients were in the study, and none died in hospital. Lymphopenia is also a marker for malnutrition. In one study, malnutrition was associated with higher mortality among men (but not women) with pneumonia. ${ }^{31}$ Hyperkalemia was an independent predictor of early mortality in our study. In a study of 463 patients with CAP from Chile, $8 \%$ of whom died in hospital, hyperkalemia was one of 25 factors associated with mortality. ${ }^{32}$ Since a number of our patients had acute renal failure, it is likely that this played a role in the hyperkalemia.

Our study has several strengths. It was prospective, and all patients with a diagnosis of CAP were enrolled. The limitations to our study include the fact that our case definition allowed nonradiologists to diagnose pneumonia on chest radiography. Approximately $25 \%$ of the patients had their chest radiographs read as "no pneumonia" by a radiologist. However interobserver and intraobserver variability in the interpretation of chest radiographs of patients with possible pneumonia by radiologists is well 
known. ${ }^{33}$ Air bronchograms, atelectasis, and COPD are usually not recognized by nonradiologists. ${ }^{33}$ Some patients with radiographs read by radiologists as no pneumonia will in fact have pneumonia. In a study ${ }^{34}$ in which simultaneously obtained high-resolution CT (HRCT) scans of the chest and chest radiographs were compared in 47 patients presenting with presumed CAP, HRCT identified all 18 cases that were apparent on chest radiography and an additional 8 cases. Thus, 8 of the 26 of the pneumonias $(31 \%)$ in this study were not identified by chest radiography. ${ }^{33}$ In a somewhat similar study ${ }^{35}$ performed on 54 hospitalized patients, additional information provided by HRCT resulted in a change in treatment plan in $39 \%$ of patients.

In conclusion, we have shown that the following factors are independently associated with mortality among patients with CAP requiring admission to hospital: pneumonia severity score, increasing age, functional status at time of hospital admission, and requirement for consultation with a respirologist or infectious diseases physician. Treatment with levofloxacin only was associated with a decreased risk of mortality. We have also shown that some of the factors associated with early mortality differ from those associated with late mortality.

ACKNOWLEDGMENT: We thank the following CAP pathway nurses: JoAnne de Jager, Linda Gardner, Lynne Korobanik, Tammy Pfeiffer, Cynthia Proskow, Sue Marshall, Nancy Baker, Nan Horne and Fredrika Herbert. The staff of EPICORE carried out data management for the project, and Jane Huang helped with data analysis.

\section{REFERENCES}

1 Jokinen C, Heiskanen L, Junvonen H, et al. Incidence of community-acquired pneumonia in the population of four municipalities in Eastern Finland. Am J Epidemiol 1993; 137:977-988

2 Guest JF, Morris A. Community-acquired pneumonia: the annual cost to the National Health Service in the UK. Eur Respir J 1997; 10:1530-1534

3 Marrie TJ, Carriere KC, Jin Y, et al. Mortality during hospitalization for pneumonia in Edmonton, Alberta is associated with physician volume. Eur Respir J 2003; 22:148-155

4 Lave JR, Fine MJ, Sankey SS, et al. Hospitalized pneumonia: outcomes, treatment patterns and costs in urban and rural areas. J Gen Intern Med 1996; 11:415-421

5 Ellrodt G, Cook DJ, Lee J, et al. Evidence-based disease management. JAMA 1997; 278:1687-1692

6 Capital Health Home Page, 2003. Available at: http://www. capitalhealth.ca; accessed March 22, 2005

7 Marrie TJ, Michalyk D, Man P, et al. A critical pathway for treating community-acquired pneumonia. Can J Contin Med Ed 2001; 13; 1:43-59

8 Fine MJ, Auble TE, Yealy DM, et al. A prediction rule to identify low risk patients with community-acquired pneumonia. N Engl J Med 1997; 336:243-250

9 Halm E, Fine MJ, Marrie TJ, et al. Time of clinical stability in patients hospitalized with community-acquired pneumo- nia. Implications for practice guidelines. JAMA 1998; 279 : 1452-1457

10 Podsiadlo D, Richardson S. The timed "Up and Go": a test of basic functional mobility for frail elderly persons. J Am Geriatr Soc 1991; 38:142-148

11 Crum RM, Anthony JC, Bassett SS, et al. Population-based norms for the mini-mental state examination by age and educational level. JAMA 1993; 269:2386-2391

12 Census metropolitan area, census agglomeration, and census tract (CMA/CA/CT) reference maps, 1996 census. Ottawa, Canada, Statistics Canada, 1997; 92F0092XPB

13 Rosenbaum PR, Rubin DB. The central role of the propensity score in observational studies for causal effects. Biometrika 1983; 70:41-55

14 D'agostino RB Jr. Propensity score methods for bias reduction in the comparison of a treatment to a non-randomized control group. Stat Med 1998; 17:2265-2281

15 Haas JS, Dean ML, Hung YY, et al. Differences in mortality among patients with community-acquired pneumonia in California by ethnicity and hospital characteristics. Am J Med 2003; 114:660-664

16 Jha AK, Shlipak MG, Hosmer W, et al. Racial differences in mortality among men hospitalized in the Veterans Affairs Health Care System. JAMA 2001; 285:297-303

17 Marrie TJ, Carriere KC, Jin Y, et al. Mortality during hospitalization for pneumonia in Edmonton, Alberta, Canada is associated with physician volume. Eur Respir J 2003; 22:148-155

18 Riquelme R, Torres A, El-Ebiary M, et al. Communityacquired pneumonia in the elderly: a multivariate analysis of risk and prognostic factors. Am J Respir Crit Care Med 1996; 154:1450-1455

19 Salive ME, Satterfield S, Ostfeld AM, et al. Disability and cognitive impairment are risk factors for pneumonia-related mortality in older adults. Public Health Rep 1993; 108:314322

20 Oga T, Nishimura K, Tsukino M, et al. Analysis of the factors related to mortality in chronic obstructive pulmonary disease: role of exercise capacity and health status. Am J Respir Crit Care Med 2003; 167:544-549

21 Davis RB, Iezzoni LI, Phillips RS, et al. Predicting in-hospital mortality: the importance of functional status. Med Care 1995; 33:906-921

22 Meehan TP, Fine MJ, Krumholz HM, et al. Quality of care, process, and outcomes in elderly patients with pneumonia. JAMA 1997; 278:2080-2084

23 Houck PM, Bratzler DW, Nsa W, et al. Timing of antibiotic administration and outcomes for Medicare patients hospitalized with community-acquired pneumonia. Arch Intern Med 2004; 164:637-644

24 Silber SH, Garrett C, Singh R, et al. Early administration of antibiotics does not shorten time to clinical stability in patients with moderate-to severe community-acquired pneumonia. Chest 2003; 124:1798-1804

25 Hartz AJ, Krakauer H, Kuhn EM, et al. Hospital characteristics and mortality rates. N Engl J Med 1989; 321:1720-1725

26 Polanczyk CA, Lane A, Coburn M, et al. Hospital outcomes in major teaching, minor teaching, and non-teaching hospitals in New York State. Am J Med 2002; 112:255-261

27 Aiken LH, Clarke SP, Sloane DM, et al. Hospital nurse staffing and patient mortality, nurse burnout and job dissatisfaction. JAMA 2002; 288:1987-1993

28 Austrian R, Gold J. Pneumococcal bacteremia with especial reference to bacteremic pneumococcal pneumonia. Ann Intern Med 1964; 60:759-776

29 Mortensen EM, Coley CM, Singer DE, et al. Causes of death for patients with community-acquired pneumonia: results of 
the Pneumonia Patient Outcomes Research Team Cohort Study. Arch Intern Med 2002; 162:1959-1964

30 Wong RS, Wu A, To KF, et al. Haematological manifestations in patients with severe acute respiratory syndrome: retrospective analysis. BMJ 2003; 326:1358-1362

31 LaCroix AZ, Lipson S, Miles TP, et al. Prospective study of pneumonia hospitalizations and mortality of U.S. older people: the role of chronic conditions, health behaviors, and nutritional status. Public Health Rep 1989; 104:350-360

32 Saldias F, Mardonez JM, Marchesse M, et al. Communityacquired pneumonia in hospitalized adult patients: clinical presentation and prognostic factors. Rev Med Chil 2002; 130:1373-1382

33 Young M, Marrie TJ. Interobserver variability in the interpretation of chest roentgenograms of patients with possible pneumonia. Arch Intern Med 1994; 154:2729-2732

34 Syrjala H, Broas M, Suramo I, et al. High-resolution computed tomography for the diagnosis of community-acquired pneumonia. Clin Infect Dis 1998; 27:358-363

35 Beall DP, Scott WW, Kuhlman JE, et al. Utilization of computed tomography in patients hospitalized with community-acquired pneumonia. Maryland Med J 1998; 47:182-187 